\title{
Los 50 años
}

\section{Dr. Christian R. Miranda-Orrillo}

Director general del Fondo Editorial Comunicacional del CMP

Director general de la Academia Peruana de Salud

El Colegio Médico del Perú (CMP) fue creado mediante Ley 15173 promulgada el 16 de octubre de 1964 . Aunque realmente empezó a funcionar en 1969, para todos los fines este año cumplimos los 50 años desde su promulgación, por ende, nuestras Bodas de Oro.

Por lo antes expuesto este año es un año muy especial, que nos invita sobre todo a reflexionar.

Las Bodas de Oro no se cumplen todos los años, por ello el CMP, sacó brillo a la excelencia que le ha caracterizado todos estos años y realizó en Marzo del presente año el IX Congreso Médico Nacional. Este magno evento rompió los fuegos de las celebraciones por los 50 años de nuestra Orden. Contó con la presencia de más de 900 delegados a nivel nacional cuya participación enriqueció el debate en relación a la Reforma de salud y permitió obtener abundante evidencia para llegar a la conclusión, que la actual política de salud, se encuentra de espaldas a la realidad nacional, e inexorablemente nos conduce a repetir los errores del pasado de nuestros países vecinos como Chile y Colombia, fomentando las Asociaciones Publicas Privadas y la entrega de Hospitales a administración privada. No prioriza la inversión del estado en el sector salud, ni fortalece la rectoría del Minsa y muy por el contrario desfinancia al sector.

Lamentamos que la actual situación del país y las pésimas condiciones laborales que no ha tocado vivir, obligue todos los años a los colegas a realizar medidas de fuerza para ser escuchados. Los que nos sentimos identificados con las reivindicaciones laborales en la orden médica en su totalidad vemos con orgullo la digna lucha de los colegas del Ministerio de Salud y la huelga médica, que ya lleva más de tres meses sin solución.

Queridos colegas este año el honorable Colegio Médico del Perú, sí , este año cumplimos medio siglo de creación y en sus casi cinco décadas de funcionamiento los miembros de la orden, hemos cumplido fielmente los principios para lo que fue creado, velando por el real cumplimiento de los principios éticos y deontológicos de todos nosotros.

Luego de 50 años, ¿es acaso osado intentar predecir los próximos 50 años de nuestro glorioso CMP? Humildemente pensamos que no. No es osado.
Conociendo lo que hemos hecho y de lo que hemos sido capaces en las primeras cinco décadas de nuestra existencia, afirmamos categóricamente que si lo deseamos, un futuro brillante nos depara. Tenemos la certeza de que el futuro pertenece a aquellos que creen en la belleza de sus sueños.

Siendo el CMP, el Colegio más representativo, el líder de opinión en salud, y uno de los más respetados por la ciudadanía, nos permitimos, una primera hipótesis, que nos llena de entusiasmo y fe en los próximos 50 años. Una Orden médica unida, solidaria fortalecida por un liderazgo y con sostenibilidad financiera, que permita continuar la obra iniciada por los visionarios de la década del sesenta. Un Colegio que descentralice sus actividades beneficiando a todos sus miembros llegando por igual a sus 27 decanatos regionales que se han creado con el pasar de estos años.

Una segunda hipótesis nos obliga a pensar en un colegio donde sus miembros acentúen sus diferencias de grupos, que se polarice nuestra institución, y permita con facilidad que un gobierno hostil, desestabilice nuestra economía, mermando nuestras capacidades de recaudación, vía aportaciones y colegiaturas. Situación que ha empezado a preocuparnos, por no estar lejos de la realidad.

Nuestro sueño es ver una Orden fortalecida por la unidad de sus miembros, que trabaja en armonía por el interés común, que deje de lado intereses personales o de grupo y que nos permita crecer en todo los aspectos del quehacer diario. Soñamos con ser una Orden que forme los salubristas de las próximas décadas, por ello urge analizar y viabilizar el Instituto de Salud y Desarrollo Humano del CMP, necesitamos dejar de ser un ente recaudador de aportaciones que finalmente benefician a seguros privados. Debemos completar el sueño de nuestro centro médico de los médicos y para los médicos, y por qué no, nuestra clínica del CMP. ¿No sería bueno beneficiarnos de los 280 millones que facturan al año los consorcios de clínicas?

Creemos que es posible comprometer el esfuerzo nacional para megaproyectos, que convierta al CMP en una institución generadora de sus propios recursos y, al mismo tiempo, nos proteja de la época de las vacas flacas, y de las pobres pensiones que para no pocos se aproxima. 